\title{
Post-meal $\beta$-cell function predicts the efficacy of glycemic control in patients with type 2 diabetes inadequately controlled by metformin monotherapy after addition of glibenclamide or acarbose
}

Po-Hsun Chen ${ }^{1 \dagger}$, Yi-Ting Tsai ${ }^{2+}$, Jun-Sing Wang ${ }^{1}$, Shi-Dou Lin ${ }^{3}$, Wen-Jane Lee ${ }^{4}$, Shih-Li Su ${ }^{3}$, I-Te Lee ${ }^{1,5}$, Shih-Te Tu ${ }^{3}$, Yao-Hsien Tseng ${ }^{1}$, Wayne H-H Sheu ${ }^{1,5,6,7}$ and Shih-Yi Lin ${ }^{1, *^{*}}$

\begin{abstract}
Background: This study aimed to explore parameters which will predict good control of $\mathrm{HbA}_{1 \mathrm{c}}$ after adding a second anti-diabetic drug in patients with type 2 diabetes mellitus (T2DM) inadequately controlled with metformin monotherapy.

Methods: Fifty-one patients (M/F: 25/26, mean age: $53.7 \pm 8.2$ years, mean glycated hemoglobin $\left.\left[\mathrm{HbA}_{1 c}\right] 8.4 \pm 1.2 \%\right)$ with T2DM inadequately controlled with metformin were randomized to add-on glibenclamide or acarbose for 16 weeks. Before and after combination therapy, the subjects underwent a 2-hour liquid mixed meal tolerance test to determine insulin secretion (HOMA- $\beta$, insulinogenic index, and disposition index [DI]) and insulin sensitivity (HOMA-IR and Matsuda insulin sensitivity index).
\end{abstract}

Results: At baseline, there was a significant inverse relationship between $\mathrm{Dl}_{120}$ and $\mathrm{HbA}_{1 c}(p=0.001)$ in all subjects. The addition of glibenclamide and acarbose improved $\mathrm{HbA}_{1 c}$ significantly from $8.6 \pm 1.6 \%$ to $7.4 \pm 1.2 \%(p<0.001)$, and from $8.2 \pm 0.8 \%$ to $7.5 \pm 0.8 \%(p<0.001)$, respectively. In the glibenclamide group, $\mathrm{DI}_{120}$ significantly increased from $51.2 \pm 24.2$ to $74.9 \pm 41.9(p<0.05)$, and in the acarbose group, from $62.5 \pm 31.4$ to $91.7 \pm 36.2(p<0.05)$, respectively. Multiple regression analyses showed that both baseline $\mathrm{HbA}_{1 c}$ and $\mathrm{Dl}_{120}$ independently predicted reduction of $\mathrm{HbA}_{1 c}$ as well as final $\mathrm{HbA}_{1 c}$ after combination therapy.

Conclusions: In patients with T2DM inadequately controlled with metformin, add-on oral anti-diabetic agent with glibenclamide or acarbose resulted in the significant $\mathrm{HbA}_{1 c}$ reduction and improvement of $\beta$-cell function. Subjects with greater baseline $\beta$-cell function reserve displayed better glycemic response in the combination therapy of metformin with glibenclamide or acarbose.

Trial registration: This study was registered in the ClinicalTrials.gov with registration number of NCT00417729.

Keywords: Beta-cell function, Disposition index, Glycated hemoglobin, Glycemic control, Metformin

\footnotetext{
* Correspondence: sylin@vghtc.gov.tw

${ }^{\dagger}$ Equal contributors

'Division of Endocrinology and Metabolism, Department of Internal

Medicine, Taichung Veterans General Hospital, No. 1650, Sect. 4, Taiwan

Boulevard, Taichung 40705, Taiwan

${ }^{5}$ School of Medicine, College of Medicine, National Yang-Ming University,

Taipei, Taiwan

Full list of author information is available at the end of the article
}

C Biomed Central (c) 2014 Chen et al.; licensee BioMed Central Ltd. This is an Open Access article distributed under the terms of the Creative Commons Attribution License (http://creativecommons.org/licenses/by/4.0), which permits unrestricted use, distribution, and reproduction in any medium, provided the original work is properly credited. The Creative Commons Public Domain Dedication waiver (http://creativecommons.org/publicdomain/zero/1.0/) applies to the data made available in this article, unless otherwise stated. 


\section{Background}

Impaired insulin secretion and insulin sensitivity are the main pathogenic defects in type 2 diabetes mellitus (T2DM), and can lead to either fasting or postprandial hyperglycemia [1]. The United Kingdom Prospective Diabetes Study (UKPDS) reports that at the diagnosis of T2DM, the pancreatic $\beta$-cell function is already half reduced, and then declines continuously despite the allocated therapy [2]. However, insulin insensitivity generally remains stable for years following the diagnosis [3]. Data from our group demonstrated that the contribution of PPG to glycemic control is equal to or greater than that of FPG across different ranges of $\mathrm{HbA}_{1 \mathrm{c}}$ [4], and that this is partly accounted by the impaired early secretory defect of $\beta$-cell function in Asians, resulting in a greater contribution of PPG to overall glycemic control $[5,6]$.

In patients with T2DM, metformin therapy is generally recommended as the first line medication for glycemic control [7]. If the patients are unable to achieve or maintain their glycemic goal, other anti-diabetic agents are usually required, but which class of drug is more suitable remains a matter of debate. It has been reported that addition of sulfonylurea or acarbose can improve glycemic control in diabetic patients who fail to reach their $\mathrm{HbA}_{1 \mathrm{c}}$ target with metformin alone, but limited data are available guiding the add-on class of oral anti-diabetic drug (OAD) in patients with T2DM inadequately controlled with metformin [7]. At present, few data are available to study the factors that influence the glycemic response after addition of glibenclamide and acarbose in patients with type 2 diabetes inadequately controlled by metformin monotherapy. Because $\beta$-cell dysfunction plays an important role in the progression of glycemic control in T2DM, it was hypothesized that underlying $\beta$-cell dysfunction may affect the glycemic control efficacy of the secondary added-on medication. Therefore, this study aimed to compare the clinical efficacy of addition of glibenclamide and acarbose and evaluate whether $\beta$-cell function could predict glycemic control (indicated as $\mathrm{HbA}_{1 \mathrm{c}}$ ) in patients with T2DM poorly controlled with metformin.

\section{Methods}

\section{Study design}

This was a 24-week, randomized, open-label, parallel study conducted at Taichung Veterans General Hospital and Changhua Christian Hospital, Taiwan. Some of the results of this study were published before [8]. In brief, outpatients with T2DM, who were 30 to 70 year-old and treated by mono- or dual- OAD therapy for above 3 months with a $\mathrm{HbA}_{1 \mathrm{c}}$ value of 7.0 to $11.0 \%$, were eligible. Total 51 subjects (mean age, 54 years; females, $51 \%$; mean body mass index (BMI), $25.6 \mathrm{~kg} / \mathrm{m}^{2}$; mean $\mathrm{HbA}_{1 \mathrm{c}}, 8.4 \%$ were randomized when they were inadequately controlled by metformin monotherapy (500 mg 3 times daily) for 8 weeks.
Anthropometric data, FPG, $\mathrm{HbA}_{1 \mathrm{c}}$, and lipid profiles were measured at baseline (randomization visit) and at the end of the study after a 16-week treatment with dual oral hypoglycemic agents. Patients were excluded if they were treated with insulin or drugs that promote weight loss, had impaired renal (serum creatinine concentration $>1.5 \mathrm{mg}$ / $\mathrm{dL}$ ) or liver (aspartate aminotransferase or alanine aminotransferase 2.5 times greater than the normal range) function, had a history of hemoglobinopathy or chronic anemia, or were women of child-bearing potential without adequate contraception. During the 16-week period of dual therapy, dosages were $50 \mathrm{mg}$ TID for acarbose and $2.5 \mathrm{mg}$ TID for glibenclamide for the first 4 weeks. For the following 12 weeks, dosages were doubled in each group, if the subjects could tolerate [8]. The present report further analyzed the relationship between $\mathrm{HbA}_{1 \mathrm{c}}$ and insulin secretion/sensitivity indices, and examined whether betacell function and insulin sensitivity were correlated with glycemic control after add-on glibenclamide or acarbose. Prior to randomization, a liquid mixed meal tolerance test (LMTT) was conducted after a 10-hour overnight fast. The liquid mixed meal contained $355.5 \mathrm{ml}$ and $399 \mathrm{kcal}$ (caloric contribution: $64 \%$ carbohydrate, $14 \%$ fat, and $22 \%$ protein). Blood samples were collected for measurement of serum glucose and insulin concentration at pre-meal $(0 \mathrm{~min})$ and at the $10^{\text {th }} \mathrm{min}, 20^{\text {th }} \mathrm{min}, 30^{\text {th }} \mathrm{min}, 60^{\text {th }} \mathrm{min}$, $90^{\text {th }} \mathrm{min}, 120^{\text {th }} \mathrm{min}$, and $180^{\text {th }}$ min via an indwelling venous catheter. $\mathrm{AUC}_{\text {glu }}$ was determined as the sum of the basal area and incremental area from 0 min to $120 \mathrm{~min}$. Insulin sensitivity was estimated by homeostasis model assessment of insulin resistance (HOMA-IR) [9] and the Matsuda insulin sensitivity index (MISI) [10]. Insulin secretion was estimated by homeostasis model assessment of $\beta$-cell function (HOMA- $\beta$ ) [9] and the insulinogenic index calculated as the ratio of incremental insulin to glucose during the first $30 \mathrm{~min}$ of the LMTT ( $\Delta$ insulin to $\Delta$ glucose $\left.=\mathrm{I}_{30}-\mathrm{I}_{0} / \mathrm{G}_{30}-\mathrm{G}_{0}\right)$ [11]. In addition, because the response of insulin secretion from $\beta$-cells to hyperglycemia is modulated by the severity of insulin resistance, we also used the disposition index (DI), which is calculated as the product of insulin sensitivity and insulin secretion [12-14]: early-phase disposition index, $\mathrm{DI}_{30}=\left[\mathrm{AUC}_{\text {ins } 30} / \mathrm{AUC}_{\text {glu } 30}\right] \times \mathrm{MISI}$ and total disposition index, $\mathrm{DI}_{120}=\left[\mathrm{AUC}_{\mathrm{ins}} 120 / \mathrm{AUC}_{\text {glu }}{ }_{120}\right] \times$ MISI. After a 16-week therapy of dual oral hypoglycemic agents, a second LMTT was performed with all patients. The study was approved by the Institutional Review Board of Taichung Veterans General Hospital and Changhua Christian Hospital, Taiwan, and all subjects provided informed consent.

\section{Laboratory measurements}

Plasma glucose was measured by the glucose oxidaseperoxidase method (Advia 1800; Siemens Healthcare Diagnostics Inc., Deerfield, Illinois). The inter- and 
intra-assay $\% \mathrm{CV}$ for glucose were both $<1.5 \%$. Serum insulin was determined using electrochemiluminescence immunoassay (Elecsys 2010; Roche Diagnostics, Indianapolis, Indiana). The inter- and intra-assay\% $\mathrm{CV}$ for insulin were $1.8 \%$ and $2.5 \%$, respectively. $\mathrm{HbA}_{1 \mathrm{c}}$ was measured by cation-exchange HPLC (HLC-723 G7; Tosoh Bioscience Ltd., Worcestershire, United Kingdom). The inter- and intra-assay\%CV for $\mathrm{HbA}_{1 \mathrm{c}}$ were both $<4.0 \%$.

\section{Statistical analyses}

Data are presented as the mean \pm standard deviation for continuous variables and percentage for categorical variables. The Chi-square test and Mann-Whitney $U$ test were used for between-group comparison. Linear regression analyses were used to determine the relationship between any one index of insulin sensitivity or secretion and glucose control parameters, such as baseline $\mathrm{HbA}_{1 \mathrm{c}}$, FPG, or $\left(\mathrm{AUC}_{\mathrm{glu}}\right)$ in $120 \mathrm{~min}$ after adjustment of age, gender, baseline BMI, and disease duration. The Wilcoxon signed rank test was used to analyze the differences in BMI, FPG, $\mathrm{HbA}_{1 \mathrm{c}}$, HOMA-IR, HOMA- $\beta$, insulinogenic index, MISI, and $\mathrm{DI}_{120}$ from baseline to the end of the study. In addition, simple correlation and multiple regression analysis were conducted to evaluate the independent relationship between either $\mathrm{HbA}_{1 \mathrm{c}}$ level or the magnitude of $\mathrm{HbA}_{1 \mathrm{c}}$ reduction after combination therapy and background factors as well as baseline insulin secretion/sensitivity indices. A p-value of less than 0.05 was considered statistically significant. Statistical analyses were performed using SPSS version 15.0 (SPSS Inc., Chicago, Illinois).

\section{Results}

The CONSORT flow diagram of this study was shown in the Figure 1. All of the 51 subjects enrolled in the present study were treated with metformin (500 mg 3 times daily) for the first 8 weeks as a washout period. After this period, 28 subjects were treated with metformin and acarbose while another 23 were treated with metformin and glibenclamide for 16 weeks. There was no significant difference in the clinical characteristics of each group before randomization (Table 1). Multiple linear regression analyses were performed to test the association between glucose control parameters and insulin secretion/sensitivity indices after metformin monotherapy and before randomization. It was shown $\mathrm{DI}_{120}$ was the only parameter inversely associated with $\mathrm{HbA}_{1 \mathrm{c}}$ after adjustment of age, gender, disease duration, and baseline BMI. Both $\mathrm{DI}_{120}$ and HOMA- $\beta$ significantly correlated with other glucose control parameters, FPG or $\mathrm{AUC}_{\mathrm{glu}}$. As for indices of insulin sensitivity or

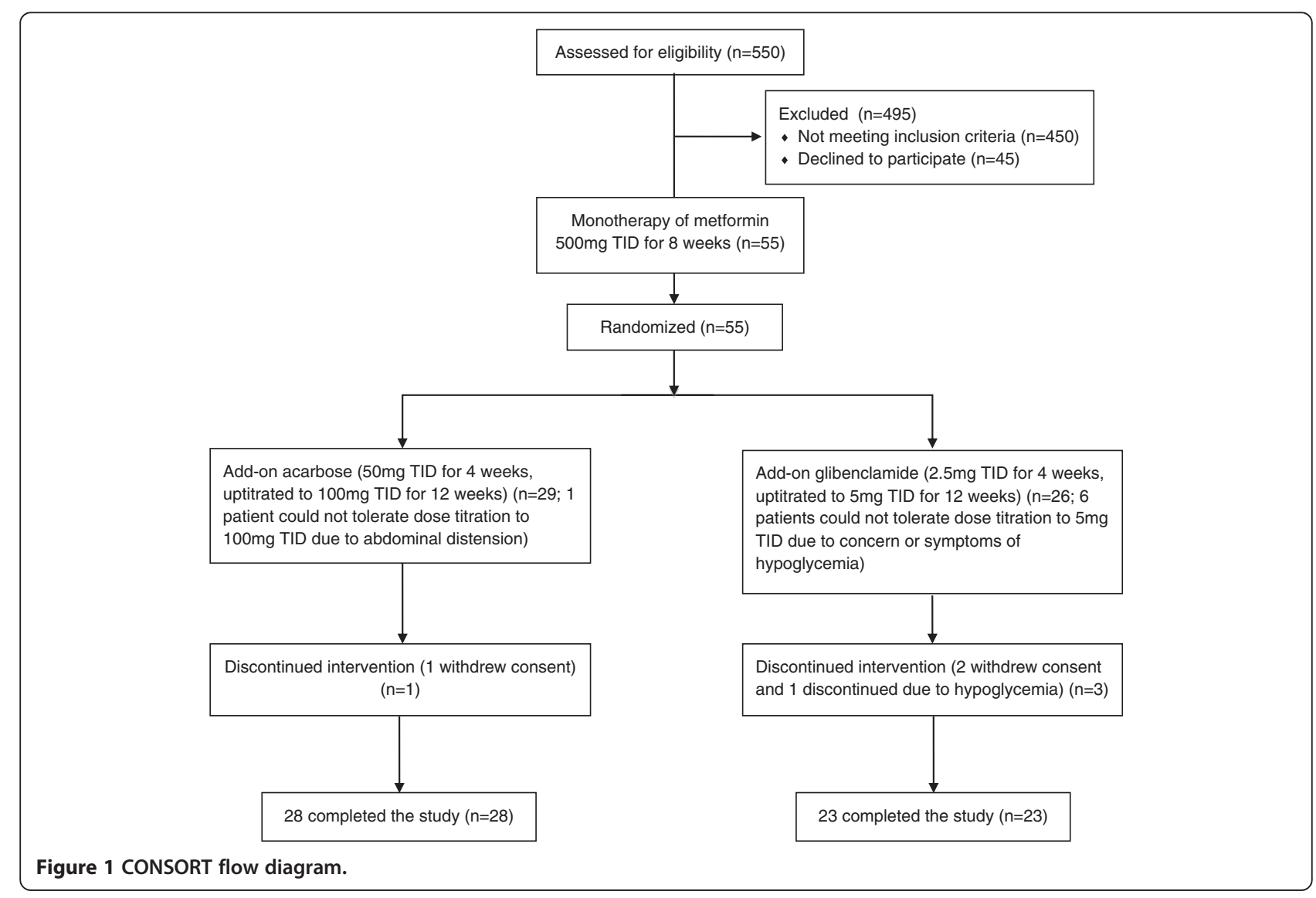


Table 1 Baseline characteristics of participants by treatment at randomization

\begin{tabular}{|c|c|c|c|c|}
\hline & All $(n=51)$ & Glibenclamide $(n=23)$ & Acarbose $(n=28)$ & $P$ value \\
\hline Gender (female, \%) & $51.0 \%$ & $56.5 \%$ & $46.4 \%$ & 0.477 \\
\hline Age (years) & $53.7 \pm 8.2$ & $54.7 \pm 8.3$ & $52.8 \pm 8.2$ & 0.378 \\
\hline Disease duration (years) & $6.9 \pm 4.6$ & $6.0 \pm 4.7$ & $7.6 \pm 4.5$ & 0.106 \\
\hline BMI $\left(\mathrm{kg} / \mathrm{m}^{2}\right)$ & $25.6 \pm 3.3$ & $25.3 \pm 3.8$ & $25.9 \pm 3.0$ & 0.334 \\
\hline $\mathrm{HbA}_{1 \mathrm{c}}(\%)$ & $8.4 \pm 1.2$ & $8.6 \pm 1.6$ & $8.2 \pm 0.8$ & 0.691 \\
\hline Fasting plasma glucose $(\mathrm{mmol} / \mathrm{l})$ & $8.5 \pm 2.3$ & $9.0 \pm 3.0$ & $8.2 \pm 1.3$ & 0.538 \\
\hline $\mathrm{Dl}_{30}$ & $41.1 \pm 25.0$ & $36.8 \pm 19.1$ & $44.7 \pm 29.0$ & 0.247 \\
\hline $\mathrm{Dl}_{120}$ & $57.3 \pm 28.6$ & $51.2 \pm 24.2$ & $62.5 \pm 31.4$ & 0.289 \\
\hline HOMA-IR & $3.7 \pm 2.9$ & $4.7 \pm 3.9$ & $2.9 \pm 1.5$ & 0.316 \\
\hline MISI & $3.4 \pm 1.8$ & $3.2 \pm 1.7$ & $3.6 \pm 1.8$ & 0.321 \\
\hline HOMA-ß (\%) & $44.9 \pm 40.4$ & $52.3 \pm 49.7$ & $38.9 \pm 30.4$ & 0.248 \\
\hline Insulinogenic index 30 (pmol/mmol) & $42.1 \pm 63.4$ & $35.0 \pm 37.2$ & $47.9 \pm 79.0$ & 0.416 \\
\hline
\end{tabular}

Chi-square test. Mann-Whitney $U$ test. Data are presented as mean \pm standard deviation or percentage of participants.

$\mathrm{DI}$, disposition index; HOMA- $\beta$, homeostasis model assessment $\beta$-cell function index; HOMA-IR, homeostasis model assessment insulin resistance index; MISI, Matsuda insulin sensitivity index.

resistance, only HOMA-IR was significantly associated with FPG (Table 2).

After 16 weeks of dual-OAD therapy, there was a significant decrease in FPG and $\mathrm{HbA}_{1 \mathrm{c}}$ values in both groups (Table 3), and eighteen of the 51 subjects (35.3\%) achieved good glycemic control of $\mathrm{HbA}_{1 \mathrm{c}}<7.0 \%$ (9 subjects, $32.1 \%$ in acarbose group and 9 subjects, $39.1 \%$ in glibenclamide group, respectively, $p=0.603)$. Although there was no difference in $\mathrm{HbA}_{1 \mathrm{c}}$ between the 2 groups after add-on therapy, the mean $\mathrm{HbA}_{1 \mathrm{c}}$ reduction in the glibenclamide arm (1.2\%) was greater than in acarbose arm $(0.7 \%)$, that was compatible with the general concept that sulfonylurea has a more potent effect upon the magnitude of $\mathrm{HbA}_{1 \mathrm{c}}$ reduction than acarbose [7]. In addition, the insulin secretion marker, $\mathrm{DI}_{120}$, improved in both groups, but there was no significant difference in these insulin secretion/sensitivity surrogates, and their change before and after combination therapy between the 2 treatment groups. Multiple linear regression analyses were performed to test the relationship between baseline $\mathrm{DI}_{120}$ and $\mathrm{HbA}_{1 \mathrm{c}}$ in all subjects after combination therapy of metformin with glibenclamide or acarbose (Table 4). By using the 3 analysis models to adjust $\mathrm{OAD}$ classes and other possible bias factors, including age, gender, disease duration, baseline BMI, and other insulin secretion/sensitivity indices, both baseline $\mathrm{HbA}_{1 \mathrm{c}}$ and $\mathrm{DI}_{120}$ were significantly associated with $\mathrm{HbA}_{1 \mathrm{c}}$ after add-on therapy. Likewise, a significant association was also found between baseline $\mathrm{DI}_{120}$ and the magnitude of $\mathrm{HbA}_{1 \mathrm{c}}$ reduction after add-on therapy (Table 5). In each subgroup, simple correlation analysis showed that there was a negative correlation between baseline $\mathrm{DI}_{120}$ and $\mathrm{HbA}_{1 \mathrm{c}}$ after dual therapy in acarbose group $(r=-0.439, p=$ $0.022)$, and in glibenclamide group $(r=-0.584, p=0.003)$, respectively.

\section{Discussion}

The main finding from the present study was that in those patients with T2DM inadequately controlled by metformin, residual $\beta$-cell function, expressed by $\mathrm{DI}_{120}$, independently predicted glycemic response after adding a $2^{\text {nd }} \mathrm{OAD}$, either glibenclamide or acarbose.

Table 2 Multiple linear regression analysis between insulin sensitivity and secretion indices and glucose control parameters before randomization

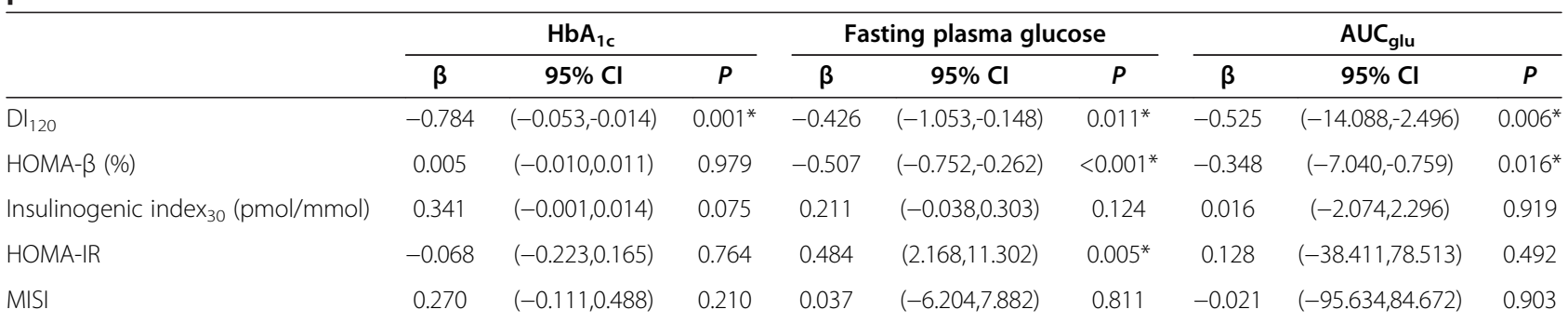

Adjusted for age, gender, body mass index, and disease duration. ${ }^{*} P<0.05$.

$A \cup C_{\text {glu }}$, area under curve of glucose in 120 min; DI, disposition index; HOMA- $\beta$, homeostasis model assessment $\beta$-cell function index; HOMA-IR, homeostasis model assessment insulin resistance index; MISI, Matsuda insulin sensitivity index. 
Table 3 Comparison of glucose control parameters, insulin secretion and sensitivity surrogates before and after treatment in both groups

\begin{tabular}{|c|c|c|c|c|c|c|}
\hline & \multicolumn{3}{|c|}{ Acarbose $(n=28)$} & \multicolumn{3}{|c|}{ Glibenclamide $(n=23)$} \\
\hline & Before & After & $P$-values vs. baseline & Before & After & $P$-values vs. baseline \\
\hline BMI $\left(\mathrm{kg} / \mathrm{m}^{2}\right)$ & $25.9 \pm 3.0$ & $25.5 \pm 3.3$ & $0.005^{*}$ & $25.3 \pm 3.8$ & $25.5 \pm 4.0$ & 0.072 \\
\hline Fasting plasma glucose (mmol/l) & $8.2 \pm 1.2$ & $7.3 \pm 1.2$ & $0.002^{*}$ & $9.0 \pm 3.0$ & $7.2 \pm 2.1$ & $0.001^{*}$ \\
\hline $\mathrm{HbA}_{1 \mathrm{c}}(\%)$ & $8.2 \pm 0.8$ & $7.5 \pm 0.8$ & $<0.001^{*}$ & $8.6 \pm 1.6$ & $7.4 \pm 1.2$ & $<0.001^{*}$ \\
\hline HOMA-IR & $3.0 \pm 1.4$ & $3.1 \pm 2.9$ & 0.682 & $4.8 \pm 3.9$ & $3.5 \pm 2.7$ & 0.101 \\
\hline HOMA- $\beta$ (\%) & $40.3 \pm 30.0$ & $49.4 \pm 40.2$ & $0.021^{*}$ & $53.7 \pm 50.5$ & $47.0 \pm 83.4$ & 0.153 \\
\hline Insulinogenic index 30 (pmol/mmol) & $47.9 \pm 79.0$ & $50.6 \pm 42.0$ & 0.080 & $35.0 \pm 37.2$ & $36.1 \pm 24.5$ & 0.191 \\
\hline MISI & $3.6 \pm 1.8$ & $4.6 \pm 2.8$ & 0.124 & $3.2 \pm 1.7$ & $4.1 \pm 2.9$ & 0.176 \\
\hline$A \cup C_{\text {ins }} 120 / A \cup C_{\text {glu }} 120^{\S}(\mathrm{pmol} / \mathrm{mmol})$ & $2.9 \pm 2.3$ & $3.8 \pm 3.1$ & $0.003^{*}$ & $2.7 \pm 1.4$ & $3.3 \pm 1.7$ & 0.121 \\
\hline $\mathrm{Dl}_{120}$ & $62.5 \pm 31.4$ & $91.7 \pm 36.2$ & $0.002^{*}$ & $51.2 \pm 24.2$ & $74.9 \pm 41.9$ & $0.003^{*}$ \\
\hline
\end{tabular}

Wilcoxon signed rank test; Data are presented as mean \pm standard deviation.

${ }^{*} \mathrm{P}<0.05$ : $\S$ total area under curve of insulin within 120 minutes divided by total area under curve of glucose within 120 minutes.

$\mathrm{DI}$, disposition index; HOMA- $\beta$, homeostasis model assessment $\beta$-cell function index; HOMA-IR, homeostasis model assesment insulin resistance index; MISI,

Matsuda insulin sensitivity index.

It is well recognized that pancreatic $\beta$-cell dysfunction is a key pathogenetic factor involved in T2DM [1]. In 1981, Bergman et al. [15] postulated the product of insulin sensitivity and insulin secretion was a constant, namely, the disposition index (DI). This index represents the responsiveness of $\beta$-cells in compensating for insulin sensitivity [16]. In general, $\mathrm{DI}_{120}$ represents the overall insulin response to insulin sensitivity during oral glucose tolerance test [12]. In addition, $\mathrm{DI}_{120}$ derived from LMTT also has a predictive power analogous to that calculated from intravenous glucose tolerance test [13,14]. In clinical studies, DI has been shown to decrease with progression from normal glucose tolerance to diabetes mellitus, and can be used to predict the development of diabetes over a long period in a population without diabetes [17]. Of note, our study also demonstrated that before randomization, there was a significant negative association between $\mathrm{DI}_{120}$ and $\mathrm{HbA}_{1 \mathrm{c}}$, but not HOMA- $\beta$, insulinogenic index, HOMA-IR, or MISI. These observations were supported by our previous report that PPG was an important contributor to glycemic control [4] and indicated that $\beta$-cell dysfunction relative to insulin sensitivity was a major determinant of $\mathrm{HbA}_{1 \mathrm{c}}$ in Asians.

There was a significant decrease in FPG and $\mathrm{HbA}_{1 \mathrm{c}}$ values after 16 weeks of dual-OAD therapy in both groups.

Table 4 Multiple linear regression models of $\mathrm{HbA}_{1 \mathrm{c}}$ after combination therapy

\begin{tabular}{|c|c|c|c|c|c|c|}
\hline & & & & & & \\
\hline & $\bar{\beta}$ & $P$ & $\beta$ & $P$ & $\beta$ & $P$ \\
\hline Drug group $(0=$ glibenclamide; $1=$ acarbose $)$ & 0.089 & 0.410 & 0.152 & 0.127 & 0.145 & 0.126 \\
\hline Gender ( $0=$ female; $1=$ male) & -0.163 & 0.110 & - & - & - & - \\
\hline Age (years) & -0.106 & 0.307 & - & - & - & - \\
\hline Disease duration (years) & 0.105 & 0.313 & - & - & - & - \\
\hline BMI $\left(\mathrm{kg} / \mathrm{m}^{2}\right)$ & 0.172 & 0.179 & - & - & - & - \\
\hline $\mathrm{HbA}_{1 c}(\%)$ & 0.677 & $<0.001^{*}$ & 0.687 & $<0.001^{*}$ & 0.703 & $<0.001^{*}$ \\
\hline MISI & 0.162 & 0.391 & 0.217 & 0.234 & - & - \\
\hline HOMA-IR & -0.305 & 0.080 & -0.210 & 0.148 & -0.244 & 0.085 \\
\hline HOMA-B (\%) & -0.030 & 0.864 & 0.029 & 0.835 & - & - \\
\hline Insulinogenic index 30 (pmol/mmol) & -0.072 & 0.734 & - & - & - & - \\
\hline$A \cup C_{\text {ins } 120} / A_{U} C_{\text {glu } 120^{\S}}(\mathrm{pmol} / \mathrm{mmol})$ & 0.301 & 0.258 & 0.302 & 0.150 & 0.158 & 0.249 \\
\hline $\mathrm{Dl}_{120}$ & -0.801 & $0.045^{*}$ & -0.743 & $0.031^{*}$ & -0.552 & $0.030^{*}$ \\
\hline $\mathrm{Dl}_{30}$ & 0.456 & 0.226 & 0.329 & 0.176 & 0.284 & 0.142 \\
\hline
\end{tabular}

Multiple linear regression models with $\mathrm{HbA}_{1 \mathrm{c}}$ after combination therapy as the dependent variable. All independent variables were collected before randomization of the second-line OADs.

${ }^{*} P<0.005$; $\S$ total area under curve of insulin within 120 minutes divided by total area under curve of glucose within 120 minutes.

DI, disposition index; HOMA- $\beta$, homeostasis model assessment $\beta$-cell function; HOMA-IR, homeostasis model assessment insulin resistance index

Incremental AUC, incremental area under curve during liquid mixed meal tolerance test; MISI, Matsuda insulin sensitivity index. 
Table 5 Multiple linear regression models of magnitude of $\mathrm{HbA}_{1 \mathrm{c}}$ reduction after combination therapy

\begin{tabular}{|c|c|c|c|c|c|c|}
\hline & \multicolumn{2}{|c|}{ Model 1} & \multicolumn{2}{|c|}{ Model 2} & \multicolumn{2}{|c|}{ Model 3} \\
\hline & $\beta$ & $P$ & $\beta$ & $P$ & $\beta$ & $P$ \\
\hline Drug group ( 0 = glibenclamide; 1 = acarbose $)$ & -0.113 & 0.410 & -0.192 & 0.127 & -0.183 & 0.126 \\
\hline Gender ( 0 = female; 1 = male) & 0.206 & 0.110 & - & - & - & - \\
\hline Age (years) & 0.134 & 0.307 & - & - & - & - \\
\hline Disease duration (years) & -0.132 & 0.313 & - & - & - & - \\
\hline BMI $\left(\mathrm{kg} / \mathrm{m}^{2}\right)$ & -0.217 & 0.179 & - & - & - & - \\
\hline $\mathrm{HbA}_{1 \mathrm{c}}(\%)$ & 0.730 & $<0.001^{*}$ & 0.718 & $<0.001^{*}$ & 0.698 & $<0.001^{*}$ \\
\hline MISI & -0.204 & 0.391 & -0.273 & 0.234 & - & - \\
\hline HOMA-IR & 0.384 & 0.080 & 0.265 & 0.148 & 0.308 & 0.085 \\
\hline HOMA-ß (\%) & 0.037 & 0.864 & -0.036 & 0.835 & - & - \\
\hline Insulinogenic index 30 (pmol/mmol) & 0.091 & 0.734 & - & - & - & - \\
\hline$A \cup C_{\text {ins } 120} / \mathrm{AUC}_{\text {glu } 120^{\S}}(\mathrm{pmol} / \mathrm{mmol})$ & -0.379 & 0.258 & -0.380 & 0.150 & -0.199 & 0.249 \\
\hline $\mathrm{Dl}_{120}$ & 1.009 & $0.045^{*}$ & 0.936 & $0.031^{*}$ & 0.696 & $0.030^{*}$ \\
\hline $\mathrm{Dl}_{30}$ & -0.574 & 0.226 & -0.414 & 0.176 & -0.358 & 0.142 \\
\hline
\end{tabular}

Multiple linear regression models with $\mathrm{HbA}_{1 \mathrm{c}}$ reduction after combination therapy as the dependent variable. All independent variables were collected before randomization of the second-line OADs.

${ }^{*} P<0.005$; $\S$ total area under curve of insulin within 120 minutes divided by total area under curve of glucose within 120 minutes.

$\mathrm{DI}$, disposition index; HOMA- $\beta$, homeostasis model assessment $\beta$-cell function; HOMA-IR, homeostasis model assessment insulin resistance index; Incremental AUC, incremental area under curve during liquid mixed meal tolerance test; MISI, Matsuda insulin sensitivity index.

It was shown that baseline $\mathrm{HbA}_{1 \mathrm{c}}$ was significantly associated with the magnitude of $\mathrm{HbA}_{1 \mathrm{c}}$ reduction after add-on therapy. Several factors, including higher baseline $\mathrm{HbA}_{1 \mathrm{c}}$, longer disease duration, younger age, and higher $\mathrm{BMI}$ have been reported to be associated with poorer glycemic control in patients with T2DM [18-20]. However, in the present study, only baseline $\mathrm{HbA}_{1 \mathrm{c}}$, but not age, disease duration, BMI, or gender, independently predicted good glycemic control after adding glibenclamide or acarbose to metformin therapy. It was speculated that a small sample size, short follow-up duration, and limited OAD classes might be causes of inconsistent results.

In addition to decreased $\mathrm{HbA}_{1 \mathrm{c}}$ after add-on second $\mathrm{OAD}$, the insulin secretion marker, $\mathrm{DI}_{120}$, also improved in both groups. It is proposed that ameliorating hyperglycemia in subjects with type 2 diabetes might also have a helpful effect on $\beta$-cell failure by attenuating so-called glucose toxicity effect [21]. Particularly, our study also found that baseline $\mathrm{DI}_{120}$ was an independent predictor of glycemic control after adding glibenclamide or acarbose in the subjects inadequately controlled by metformin monotherapy. It has been reported that $\beta$-cell dysfunction can relate to $\mathrm{HbA}_{1 \mathrm{c}}$ in newly diagnosed T2DM $[22,23]$, or in already OAD-treated adults with T2DM [24-26]. However, some of these studies were limited in that they disclosed only the cross-sectional relationship between $\beta$-cell function and glycemic parameters. Our study findings would extend the role of $\beta$-cell function in predicting the therapeutic response of $\mathrm{HbA}_{1 \mathrm{c}}$ levels. This result may be particularly important in Asian people with diabetes because it is proposed that $\beta$-cell dysfunction plays a major role in the pathogenesis of T2DM in this group of patients [5], and thus can determine $\mathrm{HbA}_{1 \mathrm{c}}$ response after use of oral hypoglycemic agents.

Several studies have reported that the addition of sulfonylurea or acarbose improved glycemic control in patients with T2DM unable to achieve or maintain glycemic control with metformin monotherapy alone $[7,27]$. It is generally accepted that sulfonylureas exert their hypoglycemic effect in part through direct action on pancreatic $\beta$-cells, which augments insulin secretion, although improvements in insulin sensitivity have also been reported in some, but not all studies [28-30]. Based on the anti-hyperglycemic mechanisms of sulfonylurea, it seemed reasonable that patients with higher baseline $\mathrm{DI}_{120}$ would have a better treatment response after adding glibencalmide, as seen in our patients.

Alpha-glucosidase inhibitors, such as acarbose, act via inhibiting disaccharide hydrolyzing enzymes in the small intestine, thereby decreasing glucose absorption and improving control over postprandial hyperglycemia. Acarbose has also been found to improve both insulin resistance and secretion indirectly in obese patients with T2DM $[31,32]$. It is postulated that insulin secretion and sensitivity might have improved at least in part through a decrease in glucose toxicity, because $\alpha$-glucosidase inhibitors do not have a direct effect on insulin secretion or sensitivity. It was speculated that the improvement in $\mathrm{HbA}_{1 \mathrm{c}}$ in the patients in the acarbose group was a result of cooperative improvement of insulin sensitivity and secretion after 
an amelioration of glucose toxicity, and thus residual $\beta$-cell function still played a role in the regulation of glycemic response after acarbose [33].

The strength of our study is the collection of insulin secretion or insulin sensitivity parameters during LMTT, which is not easily done in clinical studies. However, this LMTT was limited by that some subjects still used the investigational medication (e.g. sulfonylurea) in the evening before the $2^{\text {nd }}$ LMTT, and thus the $\mathrm{DI}_{120}$ derived from the $2^{\text {nd }}$ LMTT may reflect drug-stimulated rather than endogenous residual $\beta$-cell function. Second, our study enrolled small sample size of patients a single ethnic population, which might influence statistical power to analyze whether $\mathrm{DI}_{120}$ was a significant predictor of $\mathrm{HbA}_{1 \mathrm{c}}$ after combination therapy of metformin with glibenclamide or acarbose. Third, this study had short washout period, that might make the baseline $\mathrm{HbA}_{1 \mathrm{c}}$ at inclusion underestimated in patients taking sulfonylurea in comparison to those selected after metformin monotherapy failure. Finally, we did not evaluate the other choices of add-on medication. Further prospective studies with more patients and longer follow-up are needed to determine the association between $\mathrm{DI}_{120}$ and good glycemic control, especially in connection with different OADs.

\section{Conclusions}

Addition of glibenclamide or acarbose resulted in the significant $\mathrm{HbA}_{1 \mathrm{c}}$ reduction and improvement of $\mathrm{DI}_{120}$ in patients poorly controlled with metformin, and post-meal $\mathrm{DI}_{120}$ predicted the change in $\mathrm{HbA}_{1 \mathrm{c}}$ in each group after addition of glibenclamide or acarbose. It is suggested that residual $\beta$-cell function reserve may help to predict glycemic control response of combination of these agents.

\section{Abbreviations}

$A \cup C_{\text {glu: }}$ : Area under curve of glucose; $A \cup C_{\text {ins: }}$ Area under curve of insulin; BMI: Body mass index; DI: Disposition index; FPG: Fasting plasma glucose; HbA1c: Glycated hemoglobin; HOMA-IR: Homeostasis model assessment insulin resistance index; HOMA- $\beta$ : Homeostasis model assessment $\beta$-cell function index; LMTT: Liquid mixed meal tolerance test; MISI: Matsuda insulin sensitivity index; OAD: Oral anti-diabetic drug; PPG: Postprandial glucose; T2DM: Type 2 diabetes mellitus; UKPDS: United Kingdom prospective diabetes study.

\section{Competing interests}

I-T Lee received grants from MSD and Bayer Schering Pharma. S-T Tu has been a consultant for MSD, Bayer Schering Pharma, Eli Lilly, Astra-Zeneca, and BMS, and received honoraria from MSD, Bayer Schering Pharma, Eli Lilly, BMS, and Novo-Nordisc; he has also received grants from Bayer Schering Pharma. Wayne H-H Sheu has been a consultant for MSD, Roche, Bayer Schering Pharma, Eli Lilly, Astra-Zeneca, and BMS, and received honoraria from MSD, Roche, Bayer Schering Pharma, Eli Lilly, Astra-Zeneca, BMS, and Novo-Nordisc; he has also received grants from MSD and Bayer Schering Pharma. The other authors whose names are listed above certify that they have NO affiliations with or involvement in any organization or entity with any financial interest (such as honoraria; educational grants; participation in speakers' bureaus; membership, employment, consultancies, stock ownership, or other equity interest, and expert testimony or patent-licensing arrangements), or non-financial interest (such as personal or professional relationships, affiliations, knowledge or beliefs) in the subject matter or materials discussed in this manuscript.

\section{Authors' contributions}

$\mathrm{P}-\mathrm{HC}$ interpreted the data and wrote the manuscript; Y-TT interpreted the data and wrote the manuscript; J-SW conducted the study and performed the data collection; S-DL conducted the study; W-JL conducted the study and performed the data collection; S-LS conducted the study; I-TL conducted the study and performed data collection; S-TT conducted the study; Y-HT conducted the study; WH-HS conducted the study and interpreted the data; S-YL conducted the study, interpreted the data, and wrote the manuscript. All authors read and approved the final manuscript.

\section{Acknowledgements}

This study was supported by grants from Taichung Veterans General Hospital, Taichung, Taiwan and Bayer Schering Pharma, Taiwan Branch. The sponsors of the study were not involved in the study design, data collection, analysis, interpretation of the results, or preparation of the manuscript. Statistical analyses were supported in part by the Section of Biostatistics in Taichung Veterans General Hospital.

\section{The statement of funding sources}

This study was financially supported in part by Bayer Schering Pharma, Taiwan Branch, which was not involved in the designing of the study, data collection, analysis, interpretation of the results, or preparation of the article.

\section{Author details}

${ }^{1}$ Division of Endocrinology and Metabolism, Department of Internal Medicine, Taichung Veterans General Hospital, No. 1650, Sect. 4, Taiwan Boulevard, Taichung 40705, Taiwan. ²Department of Internal Medicine, Taichung Veterans General Hospital, Chiayi branch, Chiayi, Taiwan. ${ }^{3}$ Division of Endocrinology and Metabolism, Department of Internal Medicine, Changhua Christian Hospital, Changhua, Taiwan. ${ }^{4}$ Department of Medical Research, Taichung Veterans General Hospital, Taichung, Taiwan. ${ }^{5}$ School of Medicine, College of Medicine, National Yang-Ming University, Taipei, Taiwan. ${ }^{6}$ Department of Medicine, National Defense Medical Center, Taipei, Taiwan. ${ }^{7}$ Institute of Medical Technology, College of Life Science, National Chung-Hsing University, Taichung, Taiwan.

Received: 20 February 2014 Accepted: 26 May 2014

Published: 31 May 2014

\section{References}

1. DeFronzo RA: Pathogenesis of type 2 diabetes mellitus. Med Clin North A 2004, 88:787-835. ix

2. U.K. Prospective diabetes study group: U.K. Prospective diabetes study 16 Overview of 6 years' therapy of type II diabetes: a progressive disease. Diabetes 1995, 44:1249-1258.

3. Levy J, Atkinson AB, Bell PM, McCance DR, Hadden DR: Beta-cell deterioration determines the onset and rate of progression of secondary dietary failure in type 2 diabetes mellitus: the 10-year follow-up of the Belfast Diet Study. Diabet Med 1998, 15:290-296.

4. Wang JS, Tu ST, Lee IT, Lin SD, Lin SY, Su SL, Lee WJ, Sheu WH: Contribution of postprandial glucose to excess hyperglycaemia in Asian type 2 diabetic patients using continuous glucose monitoring. Diabetes Metab Res Rev 2011, 27:79-84.

5. Chan JC, Malik V, Jia W, Kadowaki T, Yajnik CS, Yoon KH, Hu FB: Diabetes in Asia: epidemiology, risk factors, and pathophysiology. JAMA 2009, 301:2129-2140.

6. Fukushima M, Suzuki $H$, Seino $Y$ : Insulin secretion capacity in the development from normal glucose tolerance to type 2 diabetes. Diabetes Res Clin Pract 2004, 66(Suppl 1):S37-S43

7. Inzucchi SE, Bergenstal RM, Buse JB, Diamant M, Ferrannini E, Nauck M Peters AL, Tsapas A, Wender R, Matthews DR, American Diabetes A, European Association for the Study of D: Management of hyperglycemia in type 2 diabetes: a patient-centered approach: position statement of the American Diabetes Association (ADA) and the European Association for the Study of Diabetes (EASD). Diabetes Care 2012, 35:1364-1379.

8. Wang JS, Lin SD, Lee WJ, Su SL, Lee IT, Tu ST, Tseng YH, Lin SY, Sheu WH: Effects of acarbose versus glibenclamide on glycemic excursion and oxidative stress in type 2 diabetic patients inadequately controlled by metformin: a 24-week, randomized, open-label, parallel-group comparison. Clin Ther 2011, 33:1932-1942. 
9. Matthews DR, Hosker JP, Rudenski AS, Naylor BA, Treacher DF, Turner RC: Homeostasis model assessment: insulin resistance and beta-cell function from fasting plasma glucose and insulin concentrations in man. Diabetologia 1985, 28:412-419.

10. Matsuda M, DeFronzo RA: Insulin sensitivity indices obtained from oral glucose tolerance testing: comparison with the euglycemic insulin clamp. Diabetes Care 1999, 22:1462-1470.

11. Phillips DI, Clark PM, Hales CN, Osmond C: Understanding oral glucose tolerance: comparison of glucose or insulin measurements during the oral glucose tolerance test with specific measurements of insulin resistance and insulin secretion. Diabet Med 1994, 11:286-292.

12. Cobelli C, Toffolo GM, Dalla Man C, Campioni M, Denti P, Caumo A, Butler P, Rizza R: Assessment of beta-cell function in humans, simultaneously with insulin sensitivity and hepatic extraction, from intravenous and oral glucose tests. Am J Physiol Endocrinol Metab 2007, 293:E1-E15.

13. Maki KC, Rains TM, Dicklin MR, Bell M: Repeatability of indices of insulin sensitivity and secretion from standard liquid meal tests in subjects with type 2 diabetes mellitus or normal or impaired fasting glucose. Diabetes Technol Ther 2010, 12:895-900.

14. Maki KC, Kelley KM, Lawless AL, Hubacher RL, Schild AL, Dicklin MR, Rains TM: Validation of insulin sensitivity and secretion indices derived from the liquid meal tolerance test. Diabetes Technol Ther 2011, 13:661-666.

15. Bergman RN, Phillips LS, Cobelli C: Physiologic evaluation of factors controlling glucose tolerance in man: measurement of insulin sensitivity and beta-cell glucose sensitivity from the response to intravenous glucose. J Clin Invest 1981, 68:1456-1467.

16. Bergman RN, Ader M, Huecking K, Van Citters G: Accurate assessment of beta-cell function: the hyperbolic correction. Diabetes 2002, 51(Suppl 1):S212-S220

17. Utzschneider KM, Prigeon RL, Faulenbach MV, Tong J, Carr DB, Boyko EJ, Leonetti DL, McNeely MJ, Fujimoto WY, Kahn SE: Oral disposition index predicts the development of future diabetes above and beyond fasting and 2-h glucose levels. Diabetes Care 2009, 32:335-341.

18. Giugliano D, Maiorino M, Bellastella G, Chiodini P, Esposito K: Relationship of baseline $\mathrm{HbA1c}, \mathrm{HbA} 1 \mathrm{c}$ change and $\mathrm{HbA} 1 \mathrm{c}$ target of $<7 \%$ with insulin analogues in type 2 diabetes: a meta-analysis of randomised controlled trials. Int J Clin Pract 2011, 65:602-612.

19. Khattab M, Khader YS, Al-Khawaldeh A, Ajlouni K: Factors associated with poor glycemic control among patients with type 2 diabetes. J Diabetes Complications 2010, 24:84-89.

20. Benoit SR, Fleming R, Philis-Tsimikas A, Ji M: Predictors of glycemic control among patients with Type 2 diabetes: a longitudinal study. BMC Public Health 2005, 5:36.

21. Weir GC, Bonner-Weir S: Five stages of evolving beta-cell dysfunction during progression to diabetes. Diabetes 2004, 53(Suppl 3):S16-S21.

22. Cernea S, Huțanu A, Coroş L, Dobreanu M: Assessment of beta cell function in subjects with newly diagnosed type 2 diabetes. Revista Română de Medicină de Laborator 2013, 21:145-160.

23. Albarrak Al, Luzio SD, Chassin LJ, Playle RA, Owens DR, Hovorka R: Associations of glucose control with insulin sensitivity and pancreatic beta-cell responsiveness in newly presenting type 2 diabetes. J Clin Endocrinol Metab 2002, 87:198-203.

24. Dansuntornwong B, Chanprasertyothin S, Jongjaroenprasert W, Ngarmukos C, Bunnag P, Puavilai G, Ongphiphadhanakul B: The relation between parameters from homeostasis model assessment and glycemic control in type 2 diabetes. J Med Assoc Thai 2007, 90:2284-2290.

25. Kohnert KD, Augstein P, Zander E, Heinke P, Peterson K, Freyse EJ, Hovorka $\mathrm{R}$, Salzsieder E: Glycemic variability correlates strongly with postprandial beta-cell dysfunction in a segment of type 2 diabetic patients using oral hypoglycemic agents. Diabetes Care 2009, 32:1058-1062.

26. Shim WS, Kim SK, Kim HJ, Kang ES, Ahn CW, Lim SK, Lee HC, Cha BS: Decrement of postprandial insulin secretion determines the progressive nature of type-2 diabetes. Eur J Endocrinol 2006, 155:615-622.

27. Phillips P, Karrasch J, Scott R, Wilson D, Moses R: Acarbose improves glycemic control in overweight type 2 diabetic patients insufficiently treated with metformin. Diabetes Care 2003, 26:269-273.

28. Simonson DC, Ferrannini E, Bevilacqua S, Smith D, Barrett E, Carlson R, DeFronzo RA: Mechanism of improvement in glucose metabolism after chronic glyburide therapy. Diabetes 1984, 33:838-845.
29. Kolterman OG, Gray RS, Shapiro G, Scarlett JA, Griffin J, Olefsky JM: The acute and chronic effects of sulfonylurea therapy in type II diabetic subjects. Diabetes 1984, 33:346-354.

30. Beck-Nielsen $\mathrm{H}$, Hother-Nielsen $\mathrm{O}$, Pedersen $\mathrm{O}$ : Mechanism of action of sulphonylureas with special reference to the extrapancreatic effect: an overview. Diabet Med 1988, 5:613-620.

31. Delgado H, Lehmann T, Bobbioni-Harsch E, Ybarra J, Golay A: Acarbose improves indirectly both insulin resistance and secretion in obese type 2 diabetic patients. Diabetes Metab 2002, 28:195-200.

32. Meneilly GS, Ryan EA, Radziuk J, Lau DC, Yale JF, Morais J, Chiasson JL, Rabasa-Lhoret R, Maheux P, Tessier D, Wolever T, Josse RG, Elahi D: Effect of acarbose on insulin sensitivity in elderly patients with diabetes. Diabetes Care 2000, 23:1162-1167.

33. Rosak C, Hofmann U, Paulwitz O: Modification of beta-cell response to different postprandial blood glucose concentrations by prandial repaglinide and combined acarbose/repaglinide application. Diabetes Nutr Metab 2004, 17:137-142.

doi:10.1186/1758-5996-6-68

Cite this article as: Chen et al:: Post-meal $\beta$-cell function predicts the efficacy of glycemic control in patients with type 2 diabetes inadequately controlled by metformin monotherapy after addition of glibenclamide or acarbose. Diabetology \& Metabolic Syndrome 2014 6:68.

\section{Submit your next manuscript to BioMed Central and take full advantage of:}

- Convenient online submission

- Thorough peer review

- No space constraints or color figure charges

- Immediate publication on acceptance

- Inclusion in PubMed, CAS, Scopus and Google Scholar

- Research which is freely available for redistribution 